WOt-paper 4, December 2010

Achtergronden van deze paper zijn te vinden in WOt-werkdocument 174: S. de Boer, M-J. Bogaardt, P. Kersten, F. Kistenkas, I. Neven en M. van der Zouwen (2010), De zoektocht naar nationale beleidsruimte in de EU-richtlijnen voor het milieu- en natuurbeleid. Een vergelijking van de implementatie van de Vogel- en Habitatrichtlijn, de Kaderrichtlijn Water en de Nitraatrichtlijn in Nederland, Engeland en Noordrijn-Westfalen.
(C) 2010

Alterra Wageningen UR

Postbus 47

6700 AA Wageningen

(0317) 480700

info.alterra@wur.nl www.alterra.wur.nl

\title{
Resistance is futile: you will be assimilated
}

\author{
Kroniek van de pogingen om nationale beleidsruimte te verwerven bij de implementatie van de EU Vogel- \\ en Habitatrichtlijn, de Nitraatrichtlijn en de Kaderrichtlijn Water in Nederland, Engeland en Duitsland
}

\author{
P.H. Kersten \\ Alterra Wageningen UR \\ F.R. Veeneklaas \\ Alterra Wageningen UR
}

In deze paper geven we een impressie over het onderzoek, dat Alterra en LEI Wageningen UR vanaf 2006 hebben uitgevoerd voor het toenmalige Milieu- en Natuurplanbureau ${ }^{1}$. Er is heel precies uitgezocht hoe het proces van implementatie van drie EUrichtlijnen - de Vogel- en Habitatrichtlijn, de Nitraatrichtlijn en de Kaderrichtlijn Water - is verlopen in twee landen - Nederland en Engeland - en in een Duitse deelstaat - Nordrhein-Westfalen. Doel was te analyseren hoe bij de implementatie van EU-richtlijnen nationale beleidsruimte werd gezocht en hoeveel ruimte werd gevonden. Het onderzoek beschrijft welke inspanningen men zich daarbij heeft getroost, welke strategieën zijn gehanteerd en tot welk resultaat dat uiteindelijk heeft geleid. Het onderzoek laat een terugkerend patroon zien in de manier waarop Nederland omgaat met EU-regelgeving. Recent, bij de vaststelling van de Crisis- en Herstelwet, is het patroon van perceptie en handelingen weer waar te nemen in de opstelling voor de Europese regelgeving. Dit onderstreept de actualiteit van de uitkomsten van het onderzoek.

Het onderzoek beschrijft hoe de aanvankelijke weerstand tegen de implementatie uiteindelijk wordt opgegeven en de assimilatie van de EU-regelgeving als onderdeel van de nationale beleidsomgeving plaatsvindt.

\section{Meer dan geschiedschrijving}

De resultaten van het onderzoek zijn gepubliceerd in WOt-werkdocument 174: 'De zoektocht naar nationale beleidsruimte in de EU-richtlijnen voor het milieu- en natuurbeleid' (De Boer et al., 2010). Hierin staat een zeer gedetailleerd verslag van de zoektocht naar zowel de formele als de informele beleidsruimte aan

${ }^{1}$ Het Milieu- en Natuurplanbureau is in 2009 samen met het Ruimtelijk Planbureau opgegaan in het Planbureau voor de Leefomgeving

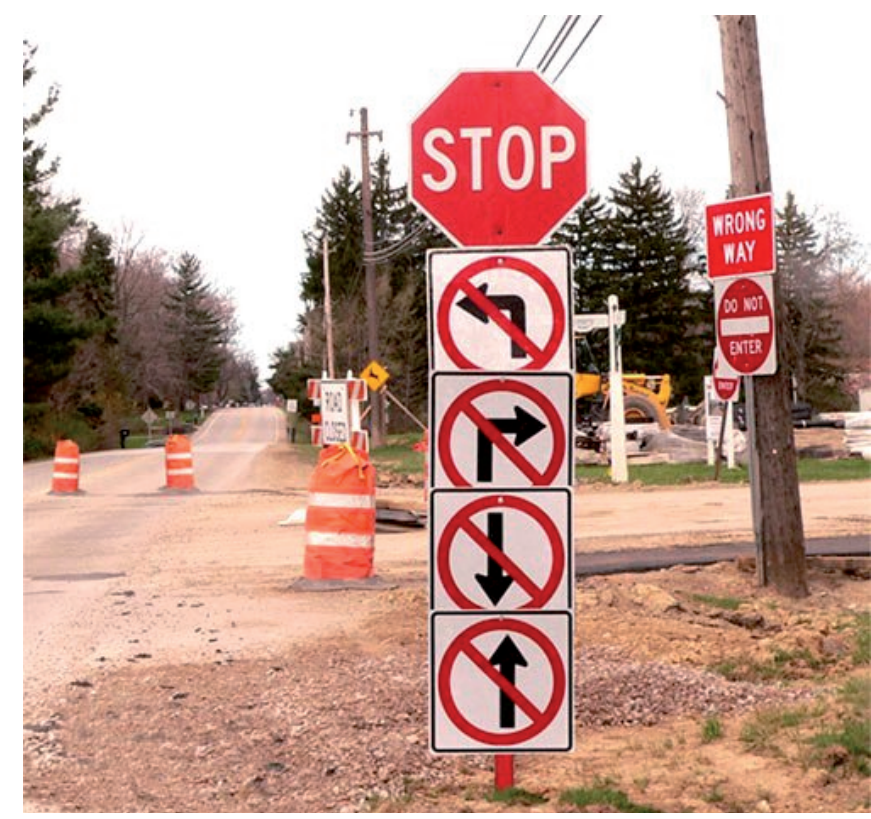

de hand van officiële documenten, uitspraken van het Europese Hof van Justitie en aangevuld met een groot aantal interviews met de betrokkenen in de drie landen. Naast deze gedetailleerde beschrijving toont een analyse aan dat bijna 200 verschillende instrumenten in de negen cases zijn gebruikt in het proces van de implementatie van de richtlijnen.

Het verslag van deze zoektocht in drie verschillende landen lijkt in eerste instantie niet meer dan dat: een nauwkeurige reconstructie, interessant voor de geschiedschrijving en als zodanig nuttig om vastgelegd te hebben. De reden om het onderzoek uit te voeren, ging echter verder: kunnen uit de reconstructie van de zoektocht naar de implementatie van drie EU-richtlijnen lessen worden getrokken over het omgaan met toekomstige EU- 
richtlijnen? Valt er iets te leren van de wijze waarop de verschillende strategieën zijn toegepast in de drie landen, in termen van succes en falen? Staat de mate van inspanning om nationale beleidsruimte te verwerven in verhouding tot de daadwerkelijk verkregen ruimte?

Het onderzoek laat zien dat er sprake is van sterke overeenkomsten tussen de ervaringen en resultaten binnen de drie landen. Er is gekeken naar de feitelijke handelingen van betrokkenen en de perceptie van deelnemers op hun rol in het onderhandelingsproces. Ondanks de grote verschillen in bestuurscultuur en variaties in het implementatieproces zijn er in grote lijnen overeenkomstige resultaten. Er is sprake van een duidelijk patroon. Na een heleboel procedureel gespartel, overlegsituaties en zelfs juridische dreigementen, wordt de EU-richtlijn uiteindelijk vrijwel ongewijzigd geimplementeerd. De gevonden nationale beleidsruimte om de richtlijn aan te passen blijkt buitengewoon klein te zijn.

Het werkdocument verwoordt het zo (hoofdstuk 8):

'Alle case-beschrijvingen laten zien dat - in lijn met de voorgaande onderzoeken naar beleidsruimte in de richtlijnen - betrokkenen allen gebruik willen maken van de mogelijkheden om bij de implementatie te komen tot specifiek maatwerk per richtlijn in de nationale context. Soms speelt mee dat weerstand tegen directe implementatie omgezet wordt in het zoeken naar beleidruimte, zoals bij het boekhoudsysteem MINAS. Zeker in de aanvang van het proces zijn handelingen erop gericht te zoeken naar de eigen interpretatie en invulling van de EU-richtlijn. In deze fase wordt beleidsruimte opgezocht en benut in de nationale uitwerkingen. Opmerkelijk is dat dit in alle beschreven negen cases uitmondt in een juridische confrontatie met de Europese Commissie bij het Europese Hof van Justitie. In het proces van toetsing, veroordeling en correctie door de EU blijkt veel van de verworven beleidsruimte achteraf toch niet echt te bestaan en komt de feitelijke implementatie veel dichter te liggen bij de oorspronkelijke letter en geest van de EU-richtlijn. Beleidsruimte kan in het proces dan ook schijnbaar verworven worden (als een gevoeld succes tijdens de uitvoering van het implementatieproces) zonder dat het in een latere fase (als de formele toetsing heeft plaatsgevonden) nog bestaat.'

\section{Inzet van 'instrumenten'}

Dit patroon en de daarbij behorende proceshandelingen zijn in het werkdocument uitgebreid terug te vinden. Het is gebaseerd op de reconstructie van negen zoektochten, bij drie richtlijnen en in drie landen. Het is ondoenlijk om alle relevante proceshandelingen in een paar pagina's samen te vatten (het rapport telt 180 pagina's). In de publicatie is voor elk van de EU-richtlijnen en elk van de landen chronologisch aangegeven welke stappen zijn gezet. Dit zijn initiatieven, acties en reacties, en interventies van zowel de lidstaten zelf als de EU-instellingen, de Europese Commissie of het Hof. In de verhalen van respondenten over de handelingen die verricht zijn, worden instrumenten genoemd en gebruikt, soms zonder dat ze als zodanig duidelijk zijn aange- geven. Betrokkenen benoemen zelf hun werkmethodes meestal niet expliciet instrumenteel. Ook invloeden uit de context werken door in de aanpak, zonder dat betrokkenen aangeven dat ze instrumenten in het proces gebruiken. In dit onderzoek zijn ze wel geëxpliciteerd en in totaal zijn er zo bijna 200 instrumenten geïdentificeerd in de negen cases. Deze lijsten van instrumenten geven als het ware een röntgenfoto van de evolutie van de regelgeving en de implementatie van de betreffende richtlijn.

Het onderzoek laat een open en tamelijk ongestructureerd zoekproces zien waarin instrumenten worden ingezet zonder ze al te zeer op hun technische kwalificaties te gebruiken. Eerder is er sprake van een automatisme en routinematig gebruik van instrumenten: 'zo doe we het hier altijd al'. In de opeenvolging van instrumenten zit een landsgebonden traditie, die een kenmerkend patroon laat zien. Het blijkt dat de inzet van instrumenten niet strak wordt gevolgd of beoordeeld tijdens de uitvoering van het proces. Daarmee ontbreekt het signaleringsbeeld of de handelingen succesvol zijn en bijdragen aan het te bereiken doel. Daarmee is ook de inzet van zoveel instrumenten duidelijke geworden: via een trial and error benadering wordt de zoektocht naar beleidsruimte (die immers in alle onderdelen van de richtlijn wel te vinden zou moeten zijn) als een open zoektocht vormgegeven. Doordat de instrumenten veelal impliciet worden ervaren, is het ook verklaarbaar dat een degelijk, meer bestuurskundige inzicht in de implementatiehandelingen ontbreekt.

Opvallend is dat de perceptie bij het begin van het implementatieproces van de beleidsruimte breed is, en niet beperkt tot de formele kaders die de richtlijn zelf aangeeft. Beleidsruimte wordt in deze beginfase vooral gezien als iets creatiefs, waarin de lidstaat volop kan zoeken naar mogelijkheden om zoveel mogelijk bestaand beleid en bestaande processen in de nieuwe richtlijn te integreren. Beleidsruimte wordt door instrumentele inzet vooral 'gevonden' in het allereerste begin van de implementatie. Naarmate het proces vordert en steeds meer instrumenten zijn ingezet, lijkt de effectiviteit van de gevonden beleidsruimte af te nemen en worden nog meer nieuwe instrumenten ingezet. Een verharding in het implementatieproces treedt op, waarna een EU-toetsing en veroordeling volgen. In de daarop volgende fase, wanneer er meer gezocht wordt naar een implementatie rechtstreeks binnen de formele kaders van de richtlijn zelf, wordt de inzet van instrumenten en het overleg anders. Er wordt tussen de lidstaten onderling informatie gedeeld.

Ook worden er, vanuit lidstaten gezamenlijk en in overleg met de EU, uitwerkingen binnen de richtlijnkaders voorgesteld en neemt de effectiviteit tot het vinden van beleidsruimte weer toe. Nationale instrumenten, die de specifieke eigenheid benadrukken, lijken veel minder effectief in het realiseren van beleidsruimte. Ook al genereren ze veel activiteiten, overleg en afstemming, de uiteindelijke doorwerking op nieuwe beleidsruimte blijkt gering. Er wordt verrassend veel tijd en moeite geïnvesteerd in de voorfase (waarin vooral de eigen nationale interpretatie een rol speelt, wat er wel binnen de richtlijn moge- 
lijk zou moeten zijn). Terwijl blijkt dat het betrekken van de EU bij de implementatie en overleg met andere lidstaten uiteindelijk meer effectieve beleidsruimte oplevert.

Het overgrote deel van de instrumenten zijn procedurele handelingen, wat past op het ontwikkelingsparcours van het implementatieproces. De grote verschillen in karakter en sturingsfilosofie tussen de onderzochte richtlijnen (van een gedetailleerde Nitraatrichtlijn naar een globalere Kaderrichtlijn Water) zien we niet terug in de manier waarop het implementatiepatroon zich ontwikkelt. Of het nu gaat om het formuleren van de richtlijnen voor gebieden, soorten en normen of om implementatieprocessen, de instrumenten die de lidstaat gebruiken, passen in het aangegeven patroon. Wel is opmerkelijk, dat lopende het proces andere instrumenten (meer formele) gaan domineren dan in het begin. Pas als er blijkt dat er individueel niet veel beleidsruimte te scoren is, wordt de internationale samenwerking opgezocht. Pas dan wordt echt duidelijk welke veranderingen op nationaal niveau in het vigerende beleid noodzakelijk zijn als gevolg van de implementatie van de desbetreffende richtlijn. Inmiddels zijn dan al heel veel instrumenten ingezet en is er al veel tijd verstreken.

\section{Verschillen en overeenkomsten tussen landen}

De zienswijze hoe met de EU en met haar richtlijnen moet worden omgegaan, laat nationaal-culturele verschillen zien. Die hangen samen met het wettelijk kader voor nadere uitwerking. Zo is het EU-regelgevingsstelsel gebaseerd op procedure, beschrijving en sanctiesystematiek, waar bijvoorbeeld in Engeland het stelsel van vrijwillige zelfbinding aan de hogere macht als sturingsstijl vigeert. De landsaard hoe om te gaan met milieuproblematiek heeft dus invloed op het implementatieproces. Wat simpel gesteld: Nederland gaat in overleg, Duitsland geeft vanuit de Bund heel duidelijke richtlijnomschrijvingen en Engeland plaatst de uitvoering van de richtlijn in het stelsel van samenwerkende non-gouvernementele organisaties.

Naast belangrijke verschillen zijn ook duidelijke overeenkomsten te zien. In alle cases is de eerste reflex de regeling vertraagd te willen implementeren, in mindere mate of heel duidelijk aangepast aan de nationaal eigen context. Ook in het verloop van het zoekproces naar beleidsruimte lopen de lidstaten in de verschillende regelingen dezelfde parkoersen. Uiteenlopend van het zoveel mogelijk willen benutten van die ruimte tot aan het ontwikkelen van het besef dat de richtlijn vooral samen met de EU en andere lidstaten moeten worden vormgegeven.

Zo heeft Nederland zich sterk ingespannen om bij de implementatie van de nitraatrichtlijn haar bijzondere positie te benadrukken (dichtbevolkt, intensieve landbouwsector). Een beroep op een uitzonderingspositie zou dan als het ware een logisch gevolg moeten zijn. Het naar voren schuiven van het, superieur geachte, Nederlandse mestboekhoudsysteem MINAS kan daarbij als voorbeeld gelden. Het onderzoek laat duidelijk zien dat dit soort vasthoudendheid niet succesvol blijkt: ten slotte moest Nederland hier inbinden. Soortgelijke ervaringen zijn opgetekend uit Engeland en Duitsland, evenals uit de ervaringen met de andere EU-richtlijnen. Er is sprake van een helder patroon, waarbij uiteindelijk de richtlijn vrijwel onaangepast werd ingevoerd. Resistance bleek inderdaad grotendeels futile zoals de Borg in de Star Trek-serie hun tegenstanders intimiderend mededelen ${ }^{2}$, in de Europese realiteit met vaak het Europese Hof van Justitie als executeur.

\section{Waarde van conclusies uit het onderzoek}

In alle cases in het onderzoek is te zien, dat er sprake was van een aanvankelijke overschatting van de beleidsruimte voor de lidstaat en voor maatwerk binnen de richtlijn. De feitelijke ruimte die gevonden is, ligt voor het grootste gedeelte binnen de formele beschrijving van de oorspronkelijke EU-richtlijn en is niet het resultaat van de inzet van nationale instrumenten. Dan gaat het om aanpassingen aan de beleidsconformiteit van de lidstaten. De creatieve zoektocht in de eerste fase is steeds tegen de formele toetsing vanuit de Europese Commissie en het Europese Hof van Justitie aangelopen. Opmerkelijk is dat een strategische overweging op het implementatieproces (wat kunnen we ermee winnen om naar extra beleidsruimte te zoeken) vooraf ontbreekt, evenals een risico-inschatting op de effectiviteit van de nationale inspanningen. Daarmee zou de relatie tussen de formele beleidsruimte in de EU-richtlijn en de nationale inzet aan instrumenten beter kunnen worden geschat. Pas wanneer er een formele terechtwijzing vanuit de EU komt, gaat het zoeken naar uitzonderingsruimte over in toepassingsinstrumentarium.

De aanbevelingen van de onderzoekers richten zich dan ook op het vergroten van de inzet van effectieve instrumenten in het implementatieproces. Niet het zoeken naar traditionele eigenheid, het willen onderhandelen of het willen aanpassen zou centraal moeten staan, maar de wens om nieuw beleid van ook onze Europese bestuursorganisaties te realiseren. Door veel beter te anticiperen (en actief deel te nemen) aan de formulering van nieuwe regelgeving in het open EU-beleidsformuleringsproces zal veel correctiewerk achteraf (zoals dat door de lidstaten wordt ervaren) voorkomen kunnen worden. En door de EU bij de implementatie van de richtlijn direct te betrekken en met andere lidstaten ervaringen uit te wisselen, kan de effectiviteit van het implementatieproces sterk toenemen. En het inzetten van instrumenten (met de daarbij benodigde proceduretijden) behoorlijk afnemen. Juist in het doorbreken van het niet altijd effectieve patroon in de omgang met de EU ligt de waarde van het onderzoek op het vlak van beleidsinnovatie.

\section{Geschiedenis herhaalt zich}

Maar toch lijkt in Nederland de geschiedenis zich steeds weer opnieuw te herhalen. Het patroon (om allereerst weer te zoeken naar uitzonderingsruimte binnen het EU-beleid om er dan tegen-

\footnotetext{
2 met vaak de, ook in dit verband wel toepasselijke, toevoeging: You will be assimilated..
} 
stribbelend aan te moeten gaan voldoen) is weer te zien bij het verzet van het Ministerie van Financiën bij de ontmanteling van de ING door eurocommissaris Kroes. Nog meer aan het patroon voldoet de recente Crisis- en Herstelwet (CHW). In deze wet wordt juridische en procedurele ruimte gezocht om projecten te realiseren. Daarbij is een eigen interpretatie gegeven van het omgaan met vigerende EU-richtlijnen: het zoeken van maximale ruimte om in bijzondere gevallen van de EU-richtlijnen af te wijken. Ook al geven experts in koor aan dat dit niet in de richtlijnen is voorzien en zo verschillende onderdelen van de $\mathrm{CHW}$ in strijd zijn met EU-regelgeving. De wet is wel aangenomen en daarmee is een claim op de EU-beleidsruimte genomen.

Ook hier is weer sprake van bijzondere geachte omstandigheden (in dit geval de financiële en economische crisis) en een eigen Nederlandse interpretatie (volgens deskundigen echt een inbreuk) op de procedures neergelegd in Europese wetgeving en richtlijnen. Het lijkt wel een erg blijmoedige inschatting (in de vorm van een enkel ambtelijk overleg met Brussel) van de beleidsruimte die Nederland zich kan veroorloven om van de feitelijke Europese regelgeving af te wijken. Onvermijdelijk zal dit ertoe leiden dat op termijn andere partijen dan de rijksoverheid zich op EU-wetten en -richtlijnen zullen beroepen en dit ook via het Europese Hof van Justitie willen afdwingen. Later zal dan wel blijken hoeveel beleidruimte er nu werkelijk is en hoeveel van de nu genomen creatieve vooral gewenste ruimte zal blijken te zijn.

Zal de Nederlandse rijksoverheid in staat zijn haar ambities met de CHW waar te maken? Of ontwaren we hier al het patroon uit het onderzoek waarin de zeer beperkte nationale speelruimte te ruim wordt geschat, leidend tot teleurstelling en uiteindelijk tot een zeer beperkte vrijheid om van de EU-regelgeving af te kunnen wijken? En daarmee het patroon dat zich in het onderzoek bij de milieu- en natuurrichtlijnen openbaarde, herhalend.

\section{Zoeken naar effectieve beleidruimte vooraan in het ontwerp}

In de beschrijving van handelingen komt het patroon steeds duidelijk in beeld. We zien dat, in plaats de EU-richtlijn te omarmen als een waardevolle bijdrage aan het stelsel van beleidsinstrumenten, er in eerste instantie actief gezocht wordt naar alle mogelijkheden om ervan af te wijken, er onderuit te komen of de regelingen te bagatelliseren. Pas na uitgebreid overleg, ambtelijke en bestuurlijke bemoeienis en dreigementen vanuit de Europese Commissie, vinden de feitelijke implementatieuitwerkingen plaats. De zich continuerende Nederlandse praktijk laat zien dat er slecht geleerd wordt uit het verleden. En dat steeds weer opnieuw tijd en energie gestoken wordt om de EU te bestrijden.
In deze paper hebben we de relevantie van het patroon in de Nederlandse omgang met de EU aangekaart als een mogelijkheid tot beleidsinnovatie. De werkelijke mogelijkheden om nationale beleidsruimte te realiseren, liggen niet achteraan in het implementatieproces, maar vooraan in de ontwerpfase van de richtlijn. Het is het moment wanneer de inhoud, procedureel kader en de uitwerkingsverplichtingen tot stand gebracht worden. In de EU-methodiek is er dan sprake van een beïnvloedbaar ontwerpproces, ondersteund door tamelijk open Groen- en Witboeken en de mogelijkheden voor lidstaten zowel informeel als formeel te participeren en te reageren.

Maar ook dan, zoals recent bij het tot stand komen van de EU-richtlijn voor territoriale cohesie, vertoont de reactie van het Nederlandse kabinet weer overeenkomsten met het patroon uit het onderzoek. Van een enthousiaste omarming van een nieuwe beleidskans lijkt niet echt sprake in de Nederlandse reactie op de vragen die de Commissie in het Groenboek aan de orde heeft gesteld. Met veel mooie woorden over het benadrukken van de eigen subsidiariteit, multi-level governance, nieuwe territoriale partnerschappen en de regionale gebiedseigenheid, wordt aan een stapje op weg naar een EU-beleid voor territoriale cohesie meegedaan. Maar het kabinet zoekt ook naar eigen nationale autonomie op dit onderwerp en neemt enige afstand van de mogelijkheid om tot een EU ruimtelijk beleid te komen. Juist in deze voorfase van de assemblage van nieuwe richtlijnen (voor Ruimte?) is beleidsruimte te ontwikkelen, in dit geval met een initiatief vanuit het Europees Parlement. Om die creatieve ruimte alsnog toe zoeken als de richtlijn er eenmaal is (en dan in de toepassing ervan), is weinig effectief gebleken. Dan is weerstand inderdaad futiel.

\section{Colofon}

De reeks 'WOt-papers' is een uitgave van de Wettelijke Onderzoekstaken (WOT) Natuur \& Milieu, onderdeel van Wageningen UR. Onderzoeksopdrachten van de WOT Natuur \& Milieu worden gefinancierd door het Ministerie van Economische Zaken, Landbouw \& Innovatie.

Wettelijke Onderzoekstaken Natuur \& Milieu

Postbus 47, 6700 AA Wageningen $\mathrm{t}$ (0317) 4854 71, f (0317) 419000

info.wnm@wur.nl, www.wotnatuurenmilieu.wur.nl 